\title{
THE IMPORTANT ROLE OF LACTATING CORNER AT PKU MUHAMMADIYAH YOGYAKARTA, INDONESIA
}

\author{
Triyani Marwati \\ Public Health Faculty, Universitas Ahmad Dahlan, Yogyakarta, Indonesia \\ email: triyanim@yahoo.com
}

\begin{abstract}
Background: Breastfeeding offers special health benefits to both infant and mother. A breastfeeding-friendly hospital might be an essential factor for predicting breastfeeding rates among women.

Method: explored the impact of breastfeeding-friendly support on the intention of mothers to continue breastfeeding, we conducted a survey to the women who visited in Muhammadiyah Hospital of Yogyakarta.

Result: The findings of the present study suggested that to encourage and increase the rate of continued breastfeeding $90 \%$ respondent understands the important of lactating corner. The respondent stated lactating corner provided good breastfeeding education to the women.

Conclusion: Hospital should establish dedicated breastfeeding rooms and maintain a comfortable and clean environment.
\end{abstract}

Keywords: exclusive breast milk, counseling on health promotion,lactation corner

\section{Background}

World breastfeeding week was initiated by WHO and UNICEF in August 1990 to protect, campaigning, and supporting breastfeeding for babies. Exclusive breastfeeding was needed for the development of babies aged 0-6 months ${ }^{1}$. Unfortunately, not all mothers implement breastfeeding because it was seen as being embarrassing to do in public ${ }^{2}$. To support the reduction of child mortality and ensure the rights of mothers and babies, the provision of lactation rooms for breastfeeding mothers should be available in all public spaces. As a result of lack of attention to this provision of lactation rooms, there was a tendency in the number of babies less than six months of the formula-fed steadily increasing and children who receive breast milk (ASI) declined exclusive ${ }^{3}$.

Scientific knowledge has demonstrated that breastfeeding was the ideal method of feeding and nurturing infants and has recognized breastfeeding as primary in achieving optimal infant health, growth and development ${ }^{4}$. Human milk was speciesspecific and offers a superior method of feeding. All other options differ markedly from it. Milk formulas were designed to mimic human milk as much as possible, but important compositional differences between human milk and formulas remain, and it was unlikely that this situation will change very soon, if ever. Thus, the breastfed infant remains the reference model against which all alternative feeding methods were measured, with regard to health, growth and development ${ }^{4}$. Human milk has a dynamic nature and varies with time postpartum, but the variations of its composition with time of lactation match the changing needs of the growing infant. The role of the pediatrician was essential in promoting, protecting and supporting breastfeeding in the hospital, medical schools, individual practices and in the community ${ }^{5}$.

The low number of children, who received six months of exclusive breastfeeding, could threaten the achievement of the Millennium Development Goals (MDGs), to reduce the number of child and maternal mortality rates by 2015 . As 
known, in 2015 , the baby mortality rate was targeted to fall from the last condition those 34 babies per 1,000 live births to 23 babies per 1,000 live births ${ }^{6}$.

Health Research (Riset Kesehatan Dasar/ Riskedas) data in 2013 showed coverage of breast milk in Indonesia was only 42 percents $^{7}$. This number was clearly below the target of $\mathrm{WHO}$, which requires coverage of breastfeeding up to 50 percents. With the birth rate in Indonesia reached 4.7 millionns per year, then the babies received breast milk for six months to two years, did not reach the two million people. Although an increase compared with the number of data Riskesdas 2007 only 32 percents coverage of breast milk, the coverage was still poor. This number also shows, the increase in coverage of breast milk per year was only about two percents. This number indicates only slight Indonesian children obtaining adequate nutrition from breast milk. Breast milk plays an important role in the process of physical and mental growth of children with long-term effects. It was also shown from the Data of National Socio-Economic Survey (Survei Sosial Ekonomi Nasional/ Susenas) in 2010 stated that only $33.6 \%$ of babies aged 0-6 months who were exclusively breastfed $^{8}$. The rate of exclusive breastfeeding in Indonesia was still low. It was caused by a variety of factors, particularly: lack of knowledge about the benefits of breastfeeding, the intense promotion of baby formula, and the increasing number of active women ${ }^{\text {. }}$.

Whereas PP. 33 in 2012, which set about exclusive breastfeeding, donor breast milk, baby formula use regulation and other baby products, regulatiaon of manufacturers or distributors aid of baby formula, witnesses related, and hospital settings and public facilities in supporting of exclusive breastfeeding program ${ }^{10}$. This low achievement could be due to the lack of support for mothers who gave birth. Especially in terms of knowledge of breast milk benefits, the intense promotion of baby formula, and career women with practical considerations. The aim of this paper to describe and to explore the impact of breastfeeding-friendly support on the intention of mothers to continue breastfeeding.

\section{Method}

Respondents were given educational intervention and the post-test was performed through the questionnaire. The survey used questionnaire constructed by the authors was applied in this study. Survey data were collected in April and May 2014 in the Muhammadiyah Hospital Yogyakarta. The primary sampling units' breastfeeding mother was selected for the interview. Face-to-face interviews used a standard questionnaire. Data collected in 2014 among 120 women (100\%) in Muhammadiyah hospital were described analyzed. A structured questionnaire survey was administered to 120 women (patient, visitor and healthcare) in Muhammadiyah Yogyakarta Hospital.

\section{Result and Discussion}

Activities have been implemented as Education Intervention:

a) Health promotion counseling on neonates

The scope of health promotion includes neonatal thermoregulation, respiration, resuscitation, bounding attachment, early breastfeeding, hygiene, sleep, elimination, and security.

b) Health promotion counseling on baby

The scope of health promotion to the baby's includes breast milk, Nutrition, Growth, Development, Bounding, Immunizations, Safety, and Sanitary. Provide health promotion of acts or circumstances relating to the health, addressed to a baby do not mean that midwives should provide direct counseling to the baby. But

KESMAS Vol. 8, No. 2, September 2014: 65 - 70 
the midwife should give the baby health promotion to the mother, the baby's father or family. Lots of scope of midwifery campaign against babies, the importance of breastfeeding as one of them. In practice, the midwife should be able to promote to the mother that breastfeeding was important for babies. Breastfeeding mothers should be advised to each mother because the first milk (colostrum) contains antibodies that can prevent infection in babies, breastfed babies rarely have gastroenteritis, fat and protein of breast milk was easily digested, can strengthen the relationship between mother and baby and breastfeeding was better, natural, sterile, fresh, cheap, available at any time. With the reasons given by the midwife through the promotion of maternal health were expected to be willing to do the advice given by midwives.

c) Health promotion counseling to children under five (toddlers)

The scope of health promotion to toddlers includes breast milk, nutrition, growth, development, interaction, immunization, socialization and security. Toddlers and children (aged 0-5 years) was one of the goals of health services performed by midwives in health promotion. Health centers, supporting health centers, village health clinic, have data on children under five in the working area. The data required for use in the implementation of health coaching for toddlers either done by midwives or other health workers, especially in health promotion. With the promotion of health in toddlers, midwives were expected to provide parents with information regarding nutrition, environmental health improvement, monitoring of growth and development of children. Family members, teachers, kindergarten or child care were involved to participate in health coaching activities. All activities were recorded and reported to the health center. Activity and health coaching services on toddlers will work well if it was supported by the village government, leaders and prominent people in the community, including the shaman. The mother should also be encouraged to check their child's health.

d) Health promotion counseling to pregnant women

The scope of health promotion against pregnant women includes physical and psychological scope. Physical scope covers nutrition, oxygen, personal hygiene, clothing, elimination, sexual, mobilization, mechanics body, pregnancy exercise, rest, immunizations, traveling, preparation of lactation, labor and delivery preparation, fetal well-being, discomfort, health education and employment. Psychological scope includes family support, health support personnel, security and comfort, preparation for parenthood, and sibling preparation. Pregnancy was a dramatic episode of the biological condition, psychological changes and adaptations of a woman who ever experienced it. Most women assume that pregnancy was a natural event that should be passed but some were regarded as a very special event. Even most pregnant women feel anxious, panicked that can lead to severe depression. Psychological support and attention will have an impact on the pattern of social life (harmony, respect, sacrifice, compassion and empathy) in pregnant women and the technical aspects, can reduce the aspect of resources (expertise, means the completion of normal delivery, acceleration, pain control and obstetrics care). These things can be done by the husband with family or midwife as health workers through health promotion.

e) Health Promotion counseling on maternal

The scope of health promotion includes maternal preparation, nutrition and fluids, support, fetal wellbeing, family involvement and reduces pain. Health promotion prevents the occurrence of maternal depression during or after childbirth. Anxious to face childbirth was a natural thing but a midwife should be 
able to overcome it. Giving maternal health promotion was one of ways. Childbirth and birth were physiological process. The birth of a baby was also a social event that mothers and families look forward to for 9 months. When childbirth begins, the mother role was to deliver the baby. The health promotion given to coping with anxiety, worry, panic and maternal depression. This promotion was much better given the day before delivery, for example during pregnancy in the third trimester.

f) Health promotion counseling to postpartum mothers

The scope of health promotion against postpartum women include nutrition and fluids, ambulation, elimination, personal hygiene and baby, rest, sexual, postpartum exercise, danger signs, family planning and breastfeeding. Midwives stay with the mother for 2 hours after childbirth. In the postnatal midwives were encouraged to inquire about the feelings of the mother. Usually mothers feel tired and weak. Mother and baby were given a chance to rest. When the mother still feels weak, health promotion can be given through the postpartum mother's family, the information to patient's family that the mother may drink and eat at all times, get up when to pee and so on. Only after the mother feel better and were willing to be given health education, midwives allowed to provide health education. Health education given for example were after giving birth mother may eat as usual, drink at least 8 glasses of water every day, mothers were taught how to breastfeed and breast care, nutrition for postpartum mothers and so on. By providing health promotion to postpartum women; it was expected that new mothers can face the parturition well and normally.

g) Health promotion counseling for breastfeeding mothers

The right of a baby was breastfed by her mother. As health promoters, midwives were expected to provide education in breastfeeding mothers. Better education given before birth, so that she can make preparations for breastfeeding mothers. The scope of health promotion given to breastfeeding mothers include personal hygiene, rest, sexual, breastfeeding, nutrition for babies, breastfeeding mothers nutrition health education, and assuring the breastfeeding mother that there were no restrictions to eat during breastfeeding. For example there was a myth that breastfeeding mothers should not eat food that smells fishy because it will cause her milk fishy. This was where the task of the midwife to straighten the myth that fishy food needed by breastfeeding mothers because it contains high protein through health promotion.

The patient survey of lactating corner from 10 April - 10 May 2012 shown $90 \%$ respondent (108 people) stated that they understand the important of breastfeeding for the children.

The respondents realize the risks if does not give breast milk to their babies. Therefore, its necessary role of healthcare worker to educate the mothers, pregnant women, and breastfeeding mothers because if they get the right information they want to breastfeed their babies. The challenge wasactually not on a volition but support. ${ }^{11}$ When informed that breastfeeding was best, all mothers will give, but often happens that they cannot breast feed due to lack of support.

Health professionals should be opportunistic about involving other family members in discussions about breast feeding whenever possible, both antenatal and postnatal. ${ }^{12}$ Eeither the families, husband or healthcare worker where she gave birth.It becomes essential thatcounsel, encourage and support mothers to initiate exclusive breastfeeding. Governments, family members and community health workers all have a role to play in the survival of newborns through the uptake of exclusive breast feeding. ${ }^{13}$

KESMAS Vol. 8, No. 2, September 2014: 65 - 70 
Lactation corner generally aims to accommodate the needs of mothers to breastfeed their babies while in a public space. ${ }^{14}$ The lactation space also educates breastfeeding mother in order to know the correct way to breastfeed. Indirectly, the existence of a lactation corner also increase the percentage of exclusive breastfeeding. Lactation Corner used for breastfeeding mothers who want to breastfeed her child in the mall and to milk for active mothers. Lactationcorner should be designed comfortable so that the mothers can breastfeed comfortably anyway. The existence of the lactation corner was expected to encourage mothers to breastfeed their children, especially active mothers. ${ }^{15}$

The existence of lactation corner and breastfeeding counselor can support the survival of breast feeding success wastaking effect on corner of lactation in the hospital. ${ }^{16}$ Lactation corner was a room that was used for milk for the visitor, patients who were in PKU Muhammadiyah Yogyakarta Hospital who were on duty, the mothers whose babies were cared for, and the mothers who were waiting for their baby checked by a doctor at the clinic.

Breastfeeding problems such as insufficient infant weight gain and reduced milk supply, sore nipples and repeat bouts of mastitis in the mother. ${ }^{17}$ Breastfeeding problems were often complained of post-hospitalization patients and preparation for breast-feeding for pregnant women in the clinic, yet optimally accommodated, because only controled when birth and immunization. Thus the presence of lactation clinic was very necessary to overcome these problems. ${ }^{18}$ Motivationwas very important to be emphasized since pregnancy, so the llactation was expected to runs well. ${ }^{19}$

Hospital interventions in support of breastfeeding have been highly successful in areas where the indigenous population has a well-established environment of breastfeeding. Lactation clinic wasorganized by the hospital to provide services to mothers that had to do with lactation during either pregnancy or postpartum. Thus a lactation clinic was an interated activityy between units related to child health, and obstetrics and gynecology. ${ }^{20}$ The clinic handles all issues related to lactation, thus the targets were mothers, pregnant women and breastfeeding mothers who come to the clinic.

Lactating corner have function to provide counseling to the mother before pregnancy, pregnant women and breastfeeding mothers. It manages breast milkused in accordance with the requirements. Educational programs were the most effective single intervention. One woman would breast-feed for up to 3 months for every 3 to 5 women attending breastfeeding educational programs. ${ }^{21}$ Educate the mother before pregnancy, pregnant women and lactating mothers in the form of knowledge about breastfeeding correctly.Transfer kknowledge of healthcare worker to mothers, pregnant women and breastfeeding mothersAccommodate the needs of mothers to breastfeed their babies while in public space.Peer counselors can effectively increase the initiation and duration of exclusive breastfeeding. ${ }^{1}$

\section{Conclusion}

The research finding showed that $90 \%$ respondent understands the important of lactating corner. The respondent stated lactating corner give good breastfeeding education to the women. Hospital should establish dedicated breastfeeding rooms and maintain a comfortable and clean environment.

\section{Reference}

1. Haider, R. et al., Effect of community-based peer counsellors on exclusive breastfeeding practices in Dhaka, Bangladesh: a randomised controlled trial, The Lancet, vol/no: 356(9242), pp.1643-1647, 2000. 
2. McIntyre, E., Hiller, J.E. and Turnbull, D., Determinants of infant feeding practices in a low socio-economic area: identifying environmental barriers to breastfeeding, Australian and New Zealand Journal of Public Health, vol/no: 23(2), pp.207-209, 1999.

3. Nwonwu, F.O.C., Millennium Development Goals: Achievements and Prospects of Meeting the Targets in Africa, African Books Collective, 2008.

4. Uauy, R. and Peirano, P., Breast is best: human milk is the optimal food for brain development, The American Journal of Clinical Nutrition, vol/no: 70(4), pp.433-434, 1999.

5. Fanaro, S., The biological specificity and superiority of human milk. Scientific basis, guarantees and safety controls, Minerva pediatrica, vol/no: 54(2), pp.113-129, 2002.

6. Bhutta, Z.A. et al., Countdown to 2015 decade report (2000-10): taking stock of maternal, newborn, and child survival, Lancet, vol/no: 375(9730), pp.2032-2044, 2010.

7. Depkes, Pokok-pokok Hasil Riskesdas Indonesia Tahun 2013, Available at: dinkes.kulonprogokab.go.id, 2013. [Accessed June 4, 2014].

8. BPS, Survei sosial ekonomi nasional 2010, Available at: sirusa.bps.go.id, 2010. [Accessed June 4, 2014].

9. Rahmathullah, L. et al., Reduced Mortality among Children in Southern India Receiving a Small Weekly Dose of Vitamin A, New England Journal of Medicine, vol/no: 323(14), pp. 929-935, 1990.

10. Depkes, PP NO 33-2012- Pemberian ASI Eksklusif, 2012. Available at: www.gizikia.depkes.go.id/download/BUKU-PP-NO-33-2012_ASI_.pdf.

11. Lewallen, L.P. et al., Breastfeeding Support and Early Cessation, Journal of Obstetric, Gynecologic, \& Neonatal Nursing, vol/no: 35(2), pp. 166-172, 2006.

12. Ingram, J. \& Johnson, D., A feasibility study of an intervention to enhance family support for breast feeding in a deprived area in Bristol, UK, Midwifery, vol/no: 20(4), pp. 367-379, 2004.

13. Anon, The importance of Exclusive Breastfeeding, 2013. Available at: http://www.healthynewbornnetwork.org/blog/importance-exclusive-breastfeeding [Accessed June 4, 2014].

14. Boyer, K., Affect, corporeality and the limits of belonging: Breastfeeding in public in the contemporary UK, Health \& Place, vol/no: 18(3), pp. 552-560, 2012.

15. Cohen, R. \& Mrtek, M.B., The Impact of Two Corporate Lactation Programs on the Incidence and Duration of Breast-Feeding by Employed Mothers, American Journal of Health Promotion, vol/no: 8(6), pp. 436-441, 1994.

16. Kistin, N., Abramson, R. \& Dublin, P., Effect of Peer Counselors on Breastfeeding Initiation, Exclusivity, and Duration Among Low-income Urban Women, Journal of Human Lactation, vol/no: 10(1), pp.11-15, 1994.

17. Marmet, C., Shell, E. \& Marmet, R., Neonatal Frenotomy May be Necessary to Correct Breastfeeding Problems, Journal of Human Lactation, vol/no: 6(3), pp. 117-121, 1990.

18. Wambach, K.A., The effect of lactation consultant contact on early breastfeeding problems, 1989. Available at: http://arizona.openrepository.com/arizona/handle/10150/277025 [Accessed July 13, 2014].

19. Meedya, S., Fahy, K. \& Kable, A., Factors that positively influence breastfeeding duration to 6 months: A literature review, Women and Birth, vol/no: 23(4), pp. 135-145, 2010.

20. Valdés, V. et al., The Impact of a Hospital and Clinic-based Breastfeeding Promotion Programme in a Middle Class Urban Environment, Journal of Tropical Pediatrics, vol/no: 39(3), pp. 142-151, 1993.

21. Guise, J.-M. et al., The Effectiveness of Primary Care-Based Interventions to Promote Breastfeeding: Systematic Evidence Review and Meta-Analysis for the US Preventive Services Task Force, The Annals of Family Medicine, vol/no: 1(2), pp. 70-78, 2003. 